\title{
RE: Parasacral transcutaneous electrical nerve stimulation in children with overactive bladder: comparison between sessions administered two and three times weekly
}

\author{
Johnnatas Mikael Lopes ${ }^{1}$, Eldys Myler Santos Marinho ${ }^{1}$, Rodolpho Nunes ${ }^{1}$ \\ ${ }^{1}$ Pós-graduação em Educação Física, Universidade Federal do Vale do São Francisco - UNIVASF, Paulo \\ Afonso, BA, Brasil
}

To the editor,

The management of overactive bladder in children is a multidisciplinary approach that requires complementary interventions. The study by Veiga et al. (1) evidences the possible effectiveness of transcutaneous electrical nerve stimulation (TENS) in the parasacral region with two (2W) and three $(3 W)$ times per week of intervention. This research was published in volume $47, n$. 4 , of this journal.

The results of Veiga et al. (1) need to be further debated in order to make better inferences. Methodologically, the absence of a placebo control group makes it impossible to state that the therapeutic effects achieved are outside the spectrum of the pathological natural history itself or by the action of urotherapy administered to both groups. (2) Answering these questions would be left only in the field of conjecture or in the confidence in other experiments with the method employed.

However, using the information provided by the authors in their results, it is possible to expand the discussion. We will analyze the results of Table-2 of the study by Veiga et al. (1), where three variables of the voiding diary were examined (urinary frequency, mean volume of urine eliminated and maximum volume of urine eliminated) and analyzed by t test and Wilcoxon test, as reported in methods. This test applies to intergroup and intragroup analysis, respectively.

It is possible to estimate the 95\% confidence intervals (95\% CI) of the groups using the means and standard deviations provided (Table-1). We noticed that the $2 \mathrm{~W}$ group with TENS is statistically different from the $3 \mathrm{~W}$ group in terms of all the variables of the voiding diary in the pre-intervention moment. Even so, the $2 \mathrm{~W}$ group of TENS showed a statistically significant and clinically moderate $(\mathrm{d}=0.40)$ reduction in urinary frequency as well as an increase in the average urinary volume $(\mathrm{d}=-0.40)$ and in the maximum volume of urine $(\mathrm{d}=-0.33)$ after the intervention. These probabilistic and clinical impact modifications were not observed in the $3 \mathrm{~W}$ group.

The application of the t test for intergroup analysis and Wilcoxon for intragroup analysis would not reveal these findings because they are not the best analysis strategy. (3) The approaches with post hoc analysis would produce control of the biased analyzes multiple. In addition, it is important to have the aid of measures of clinical effect such as Cohen's d or its similar (4). 
From this analysis, the questions arise: why does TENS $2 \mathrm{~W}$ have better effects than 3 W? Does TENS have a negative effect with $3 W$ ? Probably the best answer is that there is a main effect or interaction with urotherapy common to the groups and that perhaps it was not administered equally to the groups. It is also possible that the older age in the $3 \mathrm{~W}$ group reveals influence.
Therefore, with the findings of the present study, we cannot conclude the effect of TENS in the voiding diary variables in children with overactive bladder due to the lack of a control group, just as we cannot say that $2 \mathrm{~W}$ is better than therapy $3 \mathrm{~W}$ due to the effects of other therapies/ variables.

The Authors

Table 1 - Comparison of the variables of the voiding diary between the groups of two and three times a week of TENS.

\begin{tabular}{|c|c|c|c|c|c|c|}
\hline & \multicolumn{3}{|c|}{ Two times } & \multicolumn{3}{|c|}{ Three Times } \\
\hline & Before & After & Cohen' d & Before & After & Cohen'd \\
\hline Urinary frequency & $\begin{array}{c}10.5 \pm 3.7 \\
\text { (IC95\%:8.68-12.18) }\end{array}$ & $\begin{array}{c}6.7 \pm 1 \\
\text { (IC95\%:6.21-7.19) }\end{array}$ & 0.40 & $\begin{array}{c}7.2 \pm 0.7 \\
\text { (IC95\%:6.88-7.52) }\end{array}$ & $\begin{array}{c}7.1 \pm 0.6 \\
\text { (IC95\%:6.83- } \\
7.37)\end{array}$ & 0.03 \\
\hline $\begin{array}{l}\text { Mean volume of } \\
\text { urine voided }(\mathrm{mL})\end{array}$ & $\begin{array}{c}97.4 \pm 18.2 \\
\text { (IC95\%:95.18- } \\
99.62)\end{array}$ & $\begin{array}{c}132.5 \pm 23.7 \\
(\text { IC95\%:120.89-144.11) }\end{array}$ & -0.41 & $\begin{array}{c}117 \pm 13.4 \\
(\text { IC95\%:110.81- } \\
123.19)\end{array}$ & $\begin{array}{c}126.7 \pm 16.9 \\
\text { (IC95\%:118.89- } \\
134.50)\end{array}$ & -0.16 \\
\hline $\begin{array}{l}\text { Maximum volume } \\
\text { of urine voided } \\
(\mathrm{mL})\end{array}$ & $\begin{array}{c}186.2 \pm 34.7 \\
(\text { IC95\%:169.19- } \\
203.20)\end{array}$ & $\begin{array}{c}241 \pm 47.7 \\
\text { (IC95\%:217.63-264.37) }\end{array}$ & -0.33 & $\begin{array}{c}248.6 \pm 43 \\
(\text { IC95\%:228.74- } \\
268.46)\end{array}$ & $\begin{array}{c}233.6 \pm 21.6 \\
(\text { IC95\%:223.62- } \\
243.58)\end{array}$ & 0.11 \\
\hline
\end{tabular}

Adapted from Veiga et al. (1)

\section{CONFLICT OF INTEREST}

None declared.

\section{REFERENCES}

1. Veiga ML, Oliveira K, Batista V, Nacif A, Braga AAM, Barroso U Jr. Parasacral transcutaneous electrical nerve stimulation in children with overactive bladder: comparison between sessions administered two and three times weekly. Int Braz J Urol. 2021;47:787-93.

2. Schulz KF, Grimes DA. Generation of allocation sequences in randomised trials: chance, not choice. Lancet. 2002;359:515-9.
3. Lopes JM, Guedes MBOG, Cavalcanti RL, Souza CG. Longitudinal Data and Correlated Measures Bias: The Alternative of Mixed Models. Arq Bras Cardiol. 2019;113:1155-7.

4. Lopes JM, Andrade AS, Brito BDS, Costa IGC. Clinically significant differences: what to choose? Arq Neuropsiquiatr. 2020;78:387-8. 
Correspondence address:

Johnnatas Mikael Lopes, MD

Universidade Federal do Vale do São Francisco, UNIVASF

Rua da Liberdade, SN - Sal Torrado

Paulo Afonso, BA, 48605-560, Brasil

E-mail: johnnatas.lopes@univasf.edu.br
ARTICLE INFO

(iD) Johnnatas Mikael Lopes https://orcid.org/0000-0002-9679-5287

Int Braz J Urol. 2021; 47: 1074-6

Submitted for publication:

Abril 03, 2021

Accepted after revision:

May 10, 2021

Published as Ahead of Print:

May 20, 2021 